\section{HIV-1 WESTERN BLOT ASSAY: WHAT DETERMINES AN INDETERMINATE STATUS?}

SYED IQBAL H.*, BALAKRISHNAN P.*, SUNIL S. SOLOMON*, MURUGAVEL KG.*, KUMARASAMY N.*, VIDYA S. ${ }^{*}$, MARTIN SP. ${ }^{\star}$, THYAGARAJAN SP. ${ }^{\star \star}$, KENNETH H. MAYER ${ }^{\star \star \star}$, SOLOMON S. ${ }^{*}$

\section{ABSTRACT}

BACKGROUND: The Western blot assay is the gold standard for the detection of antibodies to human immunodeficiency virus type 1 (HIV-1). However, indeterminate Western blot reactivity to HIV-1 proteins may occur in individuals, who may not be infected with HIV. AIM: This retrospective study was aimed to determine the diagnostic value of the interpretation criteria in relation to commercial kits for HIV -1 diagnosis. METHODS AND MATERIALS: A total of 556 serum/plasma specimens collected from high-risk population attending our HIV clinic from 2000 - 2004 were tested by three different western blot kits: NEW LAV BLOT I $(n=244)$, HIV BLOT 2.2; $(n=112)$, Genetic Systems HIV-1 $(n=237)$. And the results of western blot strips were analyzed using the various interpretation criteria: WHO/NACO, CDC/ ASTPHLD, ARC, FDA, CRSS and JHU. Some specimens were run on more than one kit. RT-PCR assay was performed on 5 specimens, which were indeterminate with LAV BLOT I. RESULTS: The discrepancy in LAV BLOT I positive results were between 157(64)-176(72), and indeterminate results were between 44(18) to 63(25). No such variations were observed in genetic systems. There are some HIV negative (by PCR) specimens were indeterminate in LAV BLOT I revealing the kit more sensitive and less effective for diagnostic purpose. CONCLUSION: The genetic systems kit is superior to other kits we analyzed and its results are concordant with HIV-1 PCR results. To report, the choice of western blot commercial kit is paramount important than the use of particular interpretation criteria for the diagnosis of HIV -

Key Words: HIV diagnosis; indeterminate; interpretation criteria; Western blot.

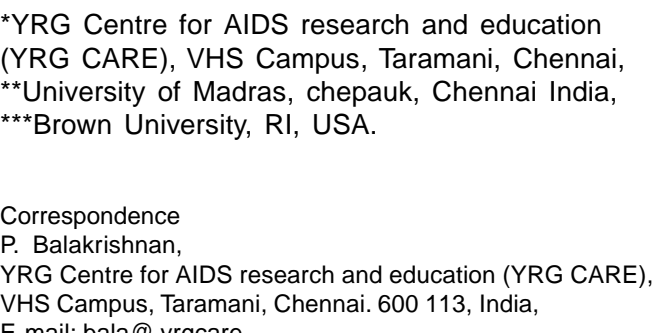

\section{INTRODUCTION}

The enzyme-linked immunosorbent assay (ELISA) is the most widely used serological test for detecting antibodies to HIV. ${ }^{[1-4]}$ Although, the Western blot assay which is often regarded as the gold standard for confirmation of HIV serostatus, indeterminate
WB profiles are frequent. ${ }^{[5]}$

Non-specific reactivity on western blot can occur with HIV negative specimens leading to inconclusive or indeterminate results. One of the most common causes of an indeterminate result is because the person tested is in the window period. Besides this, HIV-2 cross reaction, contaminating cellular antigens on viral lysate based blot strips, infection with human T-cell lymphotrophic virus I/II (HTLV $\mathrm{I} / \mathrm{II}$ ), auto antibodies, pregnancy, abnormal bilirubin levels and in-vitro hemolysis have also been suggested as possible causes of indeterminate WB status. ${ }^{[6-8]}$ Previous studies have indicated that approximately $20-30 \%$ of HIV-1 ELISA negative and $4-20 \%$ of HIV-1 ELISA positive specimens have indeterminate results by WB assay. ${ }^{[9-12]}$ The problems with indeterminate results are myriad. The recommended and widely used algorithm for the confirmation of an indeterminate result is to retest the patient after $3-6$ months. ${ }^{[9]}$ But it is infrequent that HIV-1 Western blot indeterminate specimens to become positive in follow-up. ${ }^{[5,13]}$ The problems in reporting indeterminate result to patients are many some of which include anxiety, psychological distress and the costs associated with retesting. ${ }^{[14]}$

Different regulatory bodies have proposed criteria for the interpretation of the band profiles. The differences in the sensitivity and specificity associated with each criteria may lead to differences in results for the same specimens, ${ }^{[1,5,15]}$ and has sometimes even resulted in false positive reports. ${ }^{[16]}$ Herein lies the importance in of the interpretation criteria for accurate diagnosis based on the WB band profiles. ${ }^{[15]}$
It is accepted to confirm western blot indeterminate results with immunofluorescence and Polymerase chain reaction (PCR), ${ }^{[7,15]}$ which cannot be used by all the laboratories in developing countries. Hence it is mandatory to convey about the best commercially available western blot kit to the scientific population and laboratories in this community, which gives good results. Hence this retrospective study was an attempt to determine the efficiency of kits to rule out nonspecific indeterminate (indeterminate result for a person who is not in the window period) and influence of interpretation criteria for a test, which is considered gold standard worldwide.

\section{METHODS AND MATERIALS}

This analysis was carried out in one of the leading referral centers for voluntary counseling and testing (VCT) in south India which to date has had more than 9000 clients. The Western blot results obtained between years 2000-2004 were analyzed retrospectively with banding pattern and different interpretation criteria. In this time period, a total of 556 Western blot tests were performed, all of them were included in this analysis. However we didn't had screening results for all the Western blot results, because some patients may ask only confirmatory test when they obtain screening results from other sources. All these 556 specimens are confirmed negative for HIV-2 commercial rapid HIV 1 \& 2 differentiation assay (Tridot, J.Mitra \& Co. Ltd. A-180, Okhla Ind. Area, Ph-1, New Delhi-20, India and GENIE II HIV-1/2 Biorad, 3 boulevard Raymond Poincare, 92430 MARNES LA COQUETTE - France). We have used all western blot results we had in our 
center; hence it is not aimed on unbiased or eligibility criteria for the patient's results used. As these results are from VCT centre, duplicate patient identification numbers are created to blind the laboratory personal from the patient information. Over the years three different kits were used for the WB. Initially specimens were being run on the NEW LAV BLOT I, Biorad, France (3, Boulevard Raymond Poincare, 92430 marnes la coquette, France). Then we have used HIV blot 2.2, Gene labs Diagnostics, Singapore (Genelab Diagnostics pet Itd, 85 Science park, Singapore 118259). And also we are using genetic systems ${ }^{\text {TM }}$ HIV-1 Western blot kit, Biorad, USA (Bio-Rad laboratories blood virus division Redmond, WA 98052, U.S.A), a total of 244,112 , and 237 specimens were analyzed in this products respectively. Some specimens have been run on more than one kit. Here we have tested 23 specimens on LAV BLOT I and genetic system kits. Six specimens were run on genetic systems and HIV blot 2.2. All these assay runs were validated by internal quality control provided by the manufacturer. The Western blot results were read primarily with the criteria provided by the manufacturer than they were also analyzed different widely used interpretation criteria: ${ }^{[6,17]}$ Centre for disease control (CDC)/ Association of State and Territorial Public Health Laboratory Directors (ASTPHLD), World Heath Organization (WHO)/National AIDS Control Organization (NACO, India), American Red Cross (ARC), American Food and Drug Administration (FDA), Consortium for retrovirus serology standardization (CRSS), ${ }^{[18]}$ John Hopkins University (JHU). As we found discrepancies in our results for some of the specimens run on both the LAV BLOT I and the Genetic systems kits, we randomly selected 5 among the 23 specimens and subjected them to a HIV RT-PCR ( $\mathrm{NeoDin}^{\mathrm{TM}}$ HIV type-I RT-PCR Kit, NEODIN Co., Ltd. Korea) for confirmation. We could only run 5 specimens due to limited resources. Follow up data was not available for most of the patients with indeterminate results as we rarely used the same kit during follow up.

\section{RESULTS}

In LAVBLOT I kit there are lots of differences in results when read with different interpretation criteria. To interpret the results WHO criterion was assigned by the manufacturer. There were 158 (64.7) specimens found to be positive out of 244 used in the kit. But on using the various other criteria for interpretation the number of positive results varied from 157 (64.3) to 176 (72.1), while the number of indeterminate varied between 44 (18) and 63 (25.8). No such variation was present among the negative, which implies that some of the indeterminate specimens would be considered positive if different centers used different criteria to interpret the results. CDC criterion was found to be very liberal to confirm positive results. There are minimal and no variations found in HIV BLOT 2.2 and genetic systems kits respectively. In genetic systems kit $C D C$ criteria was given to interpret the results. We identified 110 (46.4) of our specimens as positive, 111 (47) as negative and 16 as indeterminate irrespective of criteria used. This results reveals that effect of criteria are nullified with kit with better performance. A detailed record of our findings is presented in [Table 1]. No specific criterion was given by HIV BLOT 2.2 to interpret the results.

Table 1:Western blot results of the three commercial kits using different Interpretation criteria

\begin{tabular}{|c|c|c|c|c|c|c|}
\hline & $J h u^{*}$ & Who/nacot & Cdc/astphld ${ }^{*}$ & $\operatorname{Arc}{ }^{\varsigma}$ & Fdaii & Crss" \\
\hline \multicolumn{7}{|c|}{ NEW LAV BLOT I $(n=244)$} \\
\hline & $157(64.3)$ & $158(64.7)$ & $176(72.1)$ & $164(67.2)$ & $162(66.3)$ & $174(71.3)$ \\
\hline Negtt & $24(9.8)$ & $24(9.8)$ & 24(9.8) & $24(9.8)$ & $24(9.8)$ & $24(9.8)$ \\
\hline 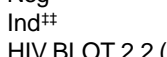 & $63(25.8)$ & $62(25.4)$ & $44(18)$ & $56(22.9)$ & $58(23.7)$ & $46(18.8)$ \\
\hline \multicolumn{7}{|c|}{ HIV BLOT 2.2 ( $N=112)$} \\
\hline $\begin{array}{l}\text { Pos } \\
\text { Nea }\end{array}$ & $\begin{array}{l}77(68.7) \\
25(22.3)\end{array}$ & $\begin{array}{ll}78(69.6) \\
25(22.3)\end{array}$ & $\begin{array}{l}78(69.6) \\
25(22.3)\end{array}$ & $\begin{array}{l}78(69.6) \\
25(22.3)\end{array}$ & $\begin{array}{l}79(70.5) \\
25(22.3)\end{array}$ & $\begin{array}{l}78(69.6) \\
25(22.3)\end{array}$ \\
\hline Ind & $10(8.9)$ & $9(8)$ & & $9(8)$ & $8(7.1)$ & $\begin{array}{l}9(8) \\
9(2<)\end{array}$ \\
\hline \multicolumn{7}{|c|}{ Genetic systems ( $n=237)$} \\
\hline Pos & $110(46.4)$ & $110(46.4)$ & $110(46.4)$ & $110(46.4)$ & $110(46.4)$ & $110(46.4)$ \\
\hline Neg & $111(47)$ & $111(47)$ & $111(47)$ & $111(47)$ & $111(47)$ & $111(47)$ \\
\hline Indeterminate & $16(7)$ & $16(7)$ & $16(7)$ & $16(7)$ & $16(7)$ & $16(7)$ \\
\hline
\end{tabular}

gp 120/gp 160 and either (or) both : p24, gp41, TTwo env Bands with or without gag or pol

‡Any two of p24, gp41, gp120/160, sOne band from each gene gag + pol + env

"p24, p31 \& gp41 (or) gp120/160, "p24 or p31 plus gp41 or gp120/160

"Positive, +NNegative, 抽ndeterminate

Of the 23 specimens that were run on both the LAV BLOT I and the genetic systems kit, we found a lot of discrepancies in the results. Based on the criteria suggested by the manufacturer the LAV BLOT I kit identified 3 specimens as positive, 4 specimens as negative and 16 specimens as indeterminate. However, the genetic systems identified only 2 specimens as positive, 7 specimens as indeterminate but 14 of these 23 specimens as negative. This implies that the LAV BLOT I could be wrongly reporting 10 negative specimens as indeterminate. On further analysis 1 out of this 10 specimens could be read positive if CDC \& CRSS criteria were used. This again proves the variations of results with respect to different criteria. Also 1 specimen indeterminate in genetic systems kit was found to be positive in LAV BLOT I kit. We also noticed that the most common band associated with an indeterminate report in the LAV BLOT I kit was the p25 band. Four of the five specimens on which the PCR was performed were reported as negative. The genetic systems kit reported three of these four as negative and one as indeterminate. The other specimen that was reported as positive by the PCR was reported as indeterminate by the genetic systems kit. The LAV BLOT I kit on the other hand reported all the five specimens as indeterminate. Summary of our interkit comparisons are presented in [Table 2]. Six specimens were run on both genetic systems kit and HIV BLOT 2.2, no variations were found in results

\section{DISCUSSION}

The results of this study indicate that the choice of best commercially available kit is important than the use of interpretation criteria. It is evident by genetic systems results with uniform number of results on different interpretation criteria. One more key finding noticed that some HIV-1 PCR negative specimens where found to be indeterminate in LAV blot I kit, those where negative in genetic systems kit. Notably an indeterminate specimen was turned out to be positive when read with WHO criterion in LAV BLOT I kit. 
Table 2: Comparison of the individual band patterns between LAV BLOT I and genetic systems with PCR $(n=23)$

\begin{tabular}{|c|c|c|c|c|c|}
\hline S. No. & LAV BLOTI & Genetic systems & $P C R^{*}$ & & \\
\hline & Bands & Result & Bands & Result & \\
\hline 1. & NOBANDS & NEG + & NOBANDS & $\mathrm{NEG}$ & - \\
\hline 2. & NOBANDS & NEG & NOBANDS & NEG & \\
\hline 3. & NOBANDS & NEG & NOBANDS & NEG & - \\
\hline 4. & NOBANDS & NEG & NOBANDS & NEG & - \\
\hline 5. & P25 & IND & NOBANDS & NEG & - \\
\hline 6. & p25 & IND & NOBANDS & NEG & - \\
\hline 7. & p25 & IND & NOBANDS & NEG & \\
\hline 8. & p25 & IND & NOBANDS & NEG & NEG \\
\hline 9. & p25 & IND & NOBANDS & NEG & \\
\hline 10. & p25 & IND & NOBANDS & NEG & NEG \\
\hline 11. & p25,p18 & IND & NOBANDS & NEG & \\
\hline 12. & $\mathrm{p} 55, \mathrm{gp} 41, \mathrm{p} 25, \mathrm{p} 18 \|$ & IND & NOBANDS & NEG & - \\
\hline 13. & p68,p25 & IND & NOBANDS & NEG & $\mathrm{NEG}$ \\
\hline 14. & p68,p55 & IND & NOBANDS & NEG & \\
\hline 15. & gp160,gp120,p34ף & POS & gp160 & IND & - \\
\hline 16. & P55 & IND & gp160,p18 & IND & \\
\hline 17. & p24 & IND & p24 & IND & POS§ \\
\hline 18. & p55 & IND & p55 & IND & NEG \\
\hline 19. & $\mathrm{p} 55, \mathrm{p} 25, \mathrm{p} 68$ & IND & p55 & IND & - \\
\hline 20. & p55,p25,p68 & IND & p55 & IND & - \\
\hline 21. & \multirow{5}{*}{ 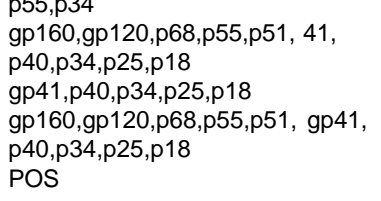 } & IND & p55 & IND & - \\
\hline \multirow[t]{4}{*}{22.} & & & & & \\
\hline & & $\begin{array}{l}\text { POS } \\
\text { POS }\end{array}$ & gp160,gp120,p68,p55,p51, & & \\
\hline & & & & & \\
\hline & & POS & $\begin{array}{c}\text { gp160,gp120,p68,p55,p51, } \\
\text { gp41,p40,p34,p25,p18 }\end{array}$ & & \\
\hline
\end{tabular}

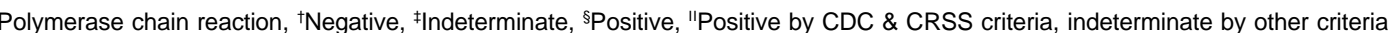

'Positive by WHO, CDC \& CRSS criteria, indeterminate by other criteria

This is crucial in India because NACO regulatory body's criterion is nothing but WHO criteria.

Our study question is to find out determinants for HIV Western blot indeterminate status. We have used kits from manufacturers in different parts of world and we have applied interpretation criteria on results to see the impact of different criteria. We have identified genetic systems kit can be used worldwide. We have PCR results for some specimens. However we have not used immunofluorescence for all the specimens and PCR for some specimens, to confirm the real status of the specimens exhibit p24 reactivity in LAV
BLOT I kit, which we accept as study limitation. Also our specimen size is very small. We were unable to analyze statistically with this small number of specimens to bring out significance. We have not used prospective specimens from patients, hence our study fails to account for possible improvements in the kit over time.

During several years, there has been an increasing number of reports describing p24 reactivity in the Western blot tes ${ }^{[14,19-21]}$ that is solely overcome in our study as erroneous and true p24 reactivity in LAV BLOT I and genetic systems respectively was proved by PCR Since, specimens indeterminate on LAB BLOT
I kit and negative on genetic system kit found to be negative for HIV-1 by PCR. Our reports strongly support earlier studies, ${ }^{[15,22]}$ that the indeterminate result with p24 itself can not predict early HIV infection, where as some others contradict these findings. ${ }^{[23]}$ The positive or indeterminate Western blot results can affect the patient mantel status, some may often spent many sleepless nights, and some may end up their lives on receiving the report. Hence these results should be interpreted very carefully and the efficient psychosocial posttest counseling is mandatory in VCT centres. Further, HIV-1 negative blood units are discarded as well as the respective donors are resisted from donating blood on the basis of repeated false positive and indeterminate Western blot results, ${ }^{[14,24,25]}$ thus the efficiency of kit plays a role in saving discarding true HIV1 negative blood units.

Further elaborative studies with PCR and immunofluorescence are needed to compare interkit performances. Also we propose that only initially reactive specimen with ELISA or rapid test should be subjected for WB analysis. It is accepted world wide that western blot is a gold standard method for the diagnosis of HIV infection with high specificity. However the one drawback of the WB is the indeterminate result. ${ }^{[1,6,9-11,15, ~ 24, ~ 26-28] ~}$ Measures are needed to restrict indeterminate results only to the patients who are in the window period. A large prospective study is needed with application of different kits and a large specimen size may be helpful to choose superior HIV diagnostic aids.

\section{REFERENCES}

1. Weber B, Hess $G$, Enzensberger R, Harms $F$ Evans CJ, Hamann A, et al. Multicenter evaluation of the novel ABN Western blot (immunoblot) system in comparison with an enzyme-linked immunosorbent assay and a different Western blot. J Clin Microbiol. 1992;30:691-7.

2. Lipniacki A, Piasek A. [Laboratory tests for HIV infection] Przegl Lek. 2003;60:478-84.

3. Grady C, Vogel S. Laboratory methods for diagnosing and monitoring HIV infection. J Assoc Nurses AIDS Care. 1993;4:11-21.

4. Chronister CL. Serologic confirmation of HIV infection. Optom Vis Sci.1995;72:299-301.

5. Meles $\mathrm{H}$, Wolday D, Fontanet A, Tsegaye A, Tilahun $\mathrm{T}$, Aklilu $\mathrm{M}$, et al. Indeterminate human immunodeficiency virus Western blot profiles in ethiopians with discordant screening-assay results. Clin Diagn Lab Immunol. 2002;9:160-3.

6. Celum CL, Coombs RW, Jones M, Murphy V, Fisher L, Grant C, et al. Risk factors for repeatedly reactive HIV-1 EIA and indeterminate western blots. A populationbased case-control study. Arch Intern Med. 1994;154:1129-37.

7. Gastaldello R, Gallego S, Isa MB, Maturano E, Sileoni S, Nates S, et al. Immunoflurescence assay reactivity patterns of serum specimens presenting indeterminate Western blot results for antibodies to HIV-1 and HTLV-I/II in Cordoba, Argentina. Rev Inst Med Trop Sao Paulo. 2001;43:277-82.

8. Silverstein DM, Aviles DH, Vehaskari VM False-positive human immunodeficiency virus antibody test in a dialysis patient. Pediatr Nephrol. 2004;19:547-9.

9. Center for Disease control. Interpretation and use of the Western blot assay for serodiagnosis of 
human immunodeficiency virus type 1 infections. Morbid. Mortal. Weekly Rep 1989;38:1-7.

10. Genesca J, Shih JW, Jett BW, Hewlett IK, Epstein JS, Alter HJ. What do western blot indeterminate patterns for human immunodeficiency virus mean in EIA-negative blood donors? Lancet 1989;2:1023-5.

11. Mac Donald KL, Jackson JB, Bowman RJ, Polesky HF, Rhame FS, Balfour $\mathrm{HH}$ et al. Performance characteristics of serologic tests for human immunodeficiency virus type 1 (HIV-1) antibody among Minnesota blood donors. Public health and clinical implications. Ann Intern Med 1989;110:617-21.

12. Schwartz. J.S.P.E.Dans, and B.P.Kinosian. Human Immunodeficiency virus test evaluation, performace, and use. JAMA 1998;259:2574-9.

13. Busch MP, Kleinman SH, Williams AE, Smith JW, Ownby HE, Laycock ME, et al. Frequency of human immunodeficiency virus (hiv) infection among contemporary anti-hiv-1 and anti-hiv-1/2 supplemental test-indeterminate blood donors. The retrovirus epidemiology donor study. Transfusion 1996;36:37-44.

14. Richard LD, Denise M, Holodniy M, Mole L, Margolis D, Blattner W, et al. Evaluation of Chiron HIV-1.HIV-2 Recombinant Immunoblot Assay. J Clin Microbiol 1996:34;2650-3.

15. Soriano V, Concheiro CL, Gutierrez M, Tuset C, Martinez-Zapico R, Ortiz de Lejarazu R, et al. Evaluation of various criteria for the interpretation of western blot for the diagnosis of human immunodeficiency virus infection. Spanish Group for the Study of HIV-2 Med Clin (Barc) 1993;100:561-6.

16. Mylonakis E, Paliou M, GreenBough TC, Flaningan TP, Letvin NL, Rich JD. Report of a False-positive HIV test result and the potential use of additional tests in establishing HIV Serostatus. Arch Intern Med 2000;160:2386-8.

17. Schochetman G, George JR. Serologic Testing for the Detection of Human Immunodeficiency Virus Infection. In: AIDS Testing. Methodology and management Issues. Springer-Verlog: Atlanta, USA; 1992;48-78.

18. Gerald SJ, George R. AIDS Testing, Methodology and Management issues. Springer-Verlag: New York USA; 1992;60:90-105.

19. Josephson SL, Swack NS, Ramirez MT, Hausle WJ Jr. Investigation of Atypical Western Blo Reactivity Involving Core Proteins of Human Immunodeficiency Virus Type 1 Journal of Clinical Microbiology 1989; 27:932-7.

20. Courouce AM, Muller JY, Richard D. False positive Western Blot reactions to human immunodeficiency virus in blood donors. Lancet 1986;2:921-2

21. Drabick JJ, Horning VL, Lennox JL, Coyne PE, Oster $\mathrm{CN}$, Knight RD, et al. A retrospective analysis of diseases associated with indeterminate HIV western blot patterns. Mil Med 1991;156:93-6.

22. Lee JH. Follow-up investigation of indeterminate western blot results for antibody to human immunodeficiency virus type 1 . J Formos Med Assoc 1994;93:283-8.

23. Chattopadhya D, Aggarwal RK, Baveja UK, Doda V, Kumari S. Evaluation of epidemiological and serological predictors of human immunodeficiency virus type-1 (HIV-1) infection among high risk professional blood donors with western blot indeterminate results. J Clin Virol 1998;11:39-49. 24. Kleinman S. Fitzpatrick L, Secord K, Wilke D. Follow-up testing and notificaton of anti-HIV Western blot atypical (indeterminate) donors Transfusion 1998;28:280-2

25. Phair J, Hoover D, Huprikar J, Detels R, Kaslow $\mathrm{R}$, Rinaldo $\mathrm{C}$, et al. The significance of western blot assays indeterminate for antibody to HIV in a cohort of homosexual/bisexual men. The Multicenter AIDS Cohort Study. J Acquir Immune Defic Syndr 1992;5:988-92.

26. Dock NL, Lamberson HV, O'Brien TA, Tribe DE, Alexander SS, Poiesz BJ. Evaluation of atypical human immunodeficiency virus immunoblo reactivity in blood donors. Transfusion
1988;28:412-8.

27. Jackson JB, MacDonald KL, Cadwell J, Sullivan $\mathrm{C}$, Kline WE, Hanson M, et al. Absence of HIV infection in blood donors with indeterminate western blot tests for antibody to HIV-1. N Engl J Med 1990;322:217-22.
28. Midthun K, Garrison L, Clements ML, Farzadegan $\mathrm{H}$, Fernie B, Quinn T. Frequency of indeterminate western blot tests in healthy adults at low risk for human immunodeficiency virus infection. The NIAID AIDS Vaccine Clinical Trails Network.J Infect Dis 1990;162:1379-82. 